\title{
Research on Stress Distribution and Failure Depth of Mining Floor During the First Weighting of Main Roof
}

\author{
Bingchao Zhao ${ }^{1,2, *}$, Zhangrong Liu ${ }^{1}$ and Chao Tong ${ }^{1}$ \\ ${ }^{I}$ School of Energy, Xi'an University of Science and Technology, Xi'an, Shaanxi, 710054, P.R. China \\ ${ }^{2}$ Key Laboratory of Western Mine Exploitation and Hazard Prevention of the Ministry of Education, Xi'an University of \\ Science and Technology, Xi'an, Shaanxi, 710054, P.R. China
}

\begin{abstract}
In order to research stress distribution and failure depth of mining floor during the first weighting of main roof, based on the analysis of abutment pressure distribution in this case, an elastic model was established to calculate the stress of any point on the floor. The expressions for this model were deduced, and a failure criterion of floor rock was put forward according to the Mohr-Coulomb failure criteria. Taking the parameters of 3612 mining face of Zhu Zhuang coal mine as an example, and through solving stress distribution of mining floor during its first weighting of main roof, stress contour and failure district of floor were determined. The result showed that, the failure depth of 3612 mining floor is $12.4 \mathrm{~m}$, which is rather close to the measured value $13 \mathrm{~m}$, thus, the utility and reliability of this study method were effeciently verified. The result provided theoretical basis for bottom grouting strengthening before the first weighting of main roof, and established theoretical foundation for further research on safe mining of confined waters.
\end{abstract}

Keywords: Failure criteria, first weighting of main roof, floor failure, stress distribution, water invasion, mining floor.

\section{INTRODUCTION}

Permo-carboniferous coal seam is mainly exploited in the eastern region of North China coal production base, where thin limestone and huge thick Ordovician limestone karst aquifer are widely developed. Between the main mining seam and the karst aquifer, there are sand-mudstone aquicludes with varied thickness $[1,2]$. With the continuous deepening of the mining level, the problem that mining floor can be affected by Ordovician limestone karst water tends to be increasingly serious. Thus, floor water invasion has gained much attention in recent years.

Affected by underground coal mining, the stress of mining floor strata is redistributed towards concentration or relief, (AUTHOR: Please re-phrase the highlighted text) causing floor strata to deform to a certain depth or even fail, which leads to significant alteration in the floors' hydraulic conductivity $[3,4]$. A large number of mine water invasion case studies show that in a certain condition of mine hydrogeology, not only high permeability channel (such as collapse column, fault, poor sealed boreholes and so on) exhibits water invasion, but also the passage created by mining [5]. Mining floor failure depth is a critical parameter for the design of waterproof coal pillar, the risk evaluation of water invasion and the determination of floor grouting reinforcement depth. Therefore, to master stress distribution and failure depth of mining floor and predict the water resisting ability of the floor accurately are rather significant in the prevention of mining floor water invasion.

*Address correspondence to this author at the School of Energy, Xi'an University of Science and Technology, Xi'an, Shaanxi, 710054, P.R. China; Tel: +86 18309269438; E-mail: 964695186@qq.com
In recent years, numerical simulation [2, 6-9] and similar material simulation $[4,10,11]$ are the two main ways to study stress distribution and failure depth of mining floor. According to the basic theory of elasticity, this paper attempted to discuss this issue with the application of analytical method.

\section{BASIC PRINCIPLE}

Assuming that there is a half-plane body with part $A B$ of its boundary being subjected to the action of normal distributed force, whose collection degree is $q$, as shown in Fig. (1), to calculate the stress of point $M(x, z)$, it is necessary to take a $d \varepsilon$ long micro segment from $A B$. The micro segment is $\varepsilon$ away from the origin of coordinate $O$, and the force $d F=q d \varepsilon$ it subjected can be considered as a small concentrated force. The stress of point $M(x, z)$ induced by $d F$ can be calculated as follows [12].

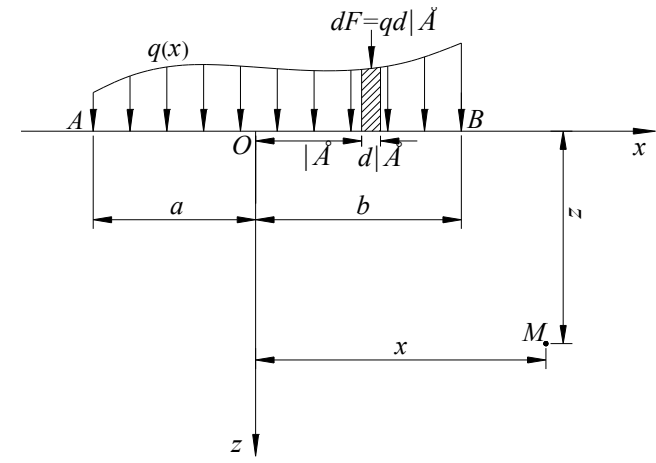

Fig. (1). Schematic diagram of distributed load on semi-infinite plane.

2015 Bentham Open 


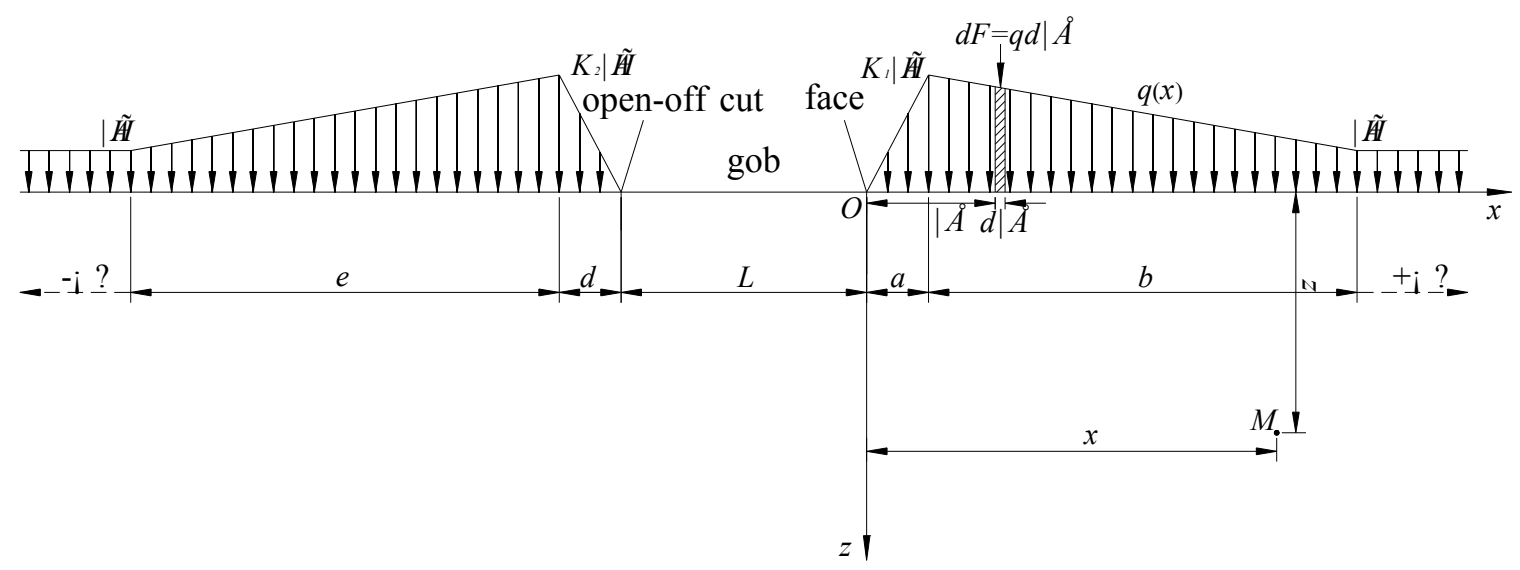

Fig. (2). Analysis of mining floor stress distribution during the first weighting of main roof.

$$
\left\{\begin{array}{l}
d \sigma_{x}=-\frac{2 q d \varepsilon}{\pi} \frac{z(x-\varepsilon)^{2}}{\left[(x-\varepsilon)^{2}+z^{2}\right]^{2}} \\
d \sigma_{z}=-\frac{2 q d \varepsilon}{\pi} \frac{z^{3}}{\left[(x-\varepsilon)^{2}+z^{2}\right]^{2}} \\
d \tau_{x z}=-\frac{2 q d \varepsilon}{\pi} \frac{(x-\varepsilon)^{2} z}{\left[(x-\varepsilon)^{2}+z^{2}\right]^{2}}
\end{array}\right.
$$

According to the principle of force superposition, the stress of point $M(x, z)$ induced by distributed force between $A$ and $B$ is derived as:

$$
\left\{\begin{array}{l}
\sigma_{x}=-\frac{2}{\pi} \int_{-a}^{b} \frac{q z(x-\varepsilon)^{2} d \varepsilon}{\left[(x-\varepsilon)^{2}+z^{2}\right]^{2}} \\
\sigma_{z}=-\frac{2}{\pi} \int_{-a}^{b} \frac{q z^{3} d \varepsilon}{\left[(x-\varepsilon)^{2}+z^{2}\right]^{2}} \\
\tau_{x z}=-\frac{2}{\pi} \int_{-a}^{b} \frac{q(x-\varepsilon) z^{2} d \varepsilon}{\left[(x-\varepsilon)^{2}+z^{2}\right]^{2}}
\end{array}\right.
$$

\section{ANALYSIS OF STRESS STATE AT ANY POINT OF THE FLOOR DURING THE FIRST WEIGHTING OF MAIN ROOF}

\subsection{Mathematical Model of The Pressure Distribution of Solid-plug Conveying Element}

During the first weighting of main roof, both the hanging area and the failure depth of mining floor reach the maximum. At this point water invasion accidents are more likely to occur[9]. Consequently, research on stress distribution and failure depth of mining floor during the first weighting of main roof is the basis of further research on floor water invasion.

Surrounding rock stress redistribution induced by coal mining not only causes stress concentration in the surrounding coal pillar, but also transfers the stress to the deep floor, altering original stress distribution [13]. With the face advancing, the magnitude and distribution of abutment pressure increase gradually. With the first weighting of main roof, the maximum value is achieved.
There have been a lot of research achievements based on the abutment pressure distribution, but unfortunately most of them did not provide the quantitative analysis. According to the distribution characteristics of measured underground pressure, the abutment pressure distribution can be simplified as linear varied distributed load, as shown in Fig. (2). The magnitude of abutment pressure can be expressed as:

$$
q(\varepsilon)=\left\{\begin{array}{lrl}
q_{1}=\gamma H, & \varepsilon \in(-\infty,-L-d-e) \\
q_{2}=\gamma H\left[\left(K_{2}-1\right) \frac{L+d+\varepsilon}{e}+K_{2}\right], & \varepsilon \in(-L-d-e,-L-d) \\
q_{3}=K_{2} \gamma H \frac{-\varepsilon-L}{d}, & \varepsilon \in(-L-d,-L) \\
q_{4}=0, & \varepsilon \in(-L, 0) \\
q_{5}=K_{1} \gamma H \frac{\varepsilon}{a}, & \varepsilon \in(0, a) \\
q_{6}=\gamma H\left[\left(K_{1}-1\right) \frac{a-\varepsilon}{b}+K_{1}\right], & \varepsilon \in(a, a+b) \\
q_{7}=\gamma H & \varepsilon \in(a+b,+\infty)
\end{array}\right.
$$

Where,

$\gamma$--- the average bulk density of overburden, $\mathrm{MN} / \mathrm{m}^{2}$;

$K_{1}$-.-- the abutment pressure concentration factor before the mining face

$K_{2}$--- the abutment pressure concentration factor after the mining face;

$H$---the buried depth of coal seam, m;

$a$--- the distance between face and the peak point of front abutment pressure, $\mathrm{m}$;

$b$--- the distance between the peak point of front abutment pressure and its boundary, $\mathrm{m}$;

$d$---the distance between open - off cut and the peak point of rear abutment pressure, $\mathrm{m}$;

$e$---the distance between the peak point of rear abutment pressure and its boundary, $\mathrm{m}$;

$L$--- the first weighting interval of main roof, $\mathrm{m}$.

According to equation (2) and equation (3), the stress of point $M(x, z)$ induced by distributed force between $A$ and $B$ is derived as 


$$
\left\{\begin{aligned}
\sigma_{x}= & -\frac{2}{\pi}\left(\int_{-\infty}^{-L-d-e} q_{1} f_{1} d \varepsilon+\int_{-L-d-e}^{-L-d} q_{2} f_{1} d \varepsilon+\int_{-L-d}^{-L} q_{3} f_{1} d \varepsilon\right. \\
& \left.+\int_{0}^{a} q_{5} f_{1} d \varepsilon+\int_{a}^{a+b} q_{6} f_{1} d \varepsilon+\int_{a+b}^{+\infty} q_{7} f_{1} d \varepsilon\right) \\
\sigma_{z}= & -\frac{2}{\pi}\left(\int_{-\infty}^{-L-d-e} q_{1} f_{2} d \varepsilon+\int_{-L-d-e}^{-L-d} q_{2} f_{2} d \varepsilon+\int_{-L-d}^{-L} q_{3} f_{2} d \varepsilon\right. \\
& \left.+\int_{0}^{a} q_{5} f_{2} d \varepsilon+\int_{a}^{a+b} q_{6} f_{2} d \varepsilon+\int_{a+b}^{+\infty} q_{7} f_{2} d \varepsilon\right) \\
\tau_{x z}= & -\frac{2}{\pi}\left(\int_{-\infty}^{-L-d-e} q_{1} f_{3} d \varepsilon+\int_{-L-d-e}^{-L-d} q_{2} f_{3} d \varepsilon+\int_{-L-d}^{-L} q_{3} f_{3} d \varepsilon\right. \\
& \left.+\int_{0}^{a} q_{5} f_{3} d \varepsilon+\int_{a}^{a+b} q_{6} f_{3} d \varepsilon+\int_{a+b}^{+\infty} q_{7} f_{3} d \varepsilon\right)
\end{aligned}\right.
$$

where $\quad f_{1}=\frac{z(x-\varepsilon)^{2}}{\left[(x-\varepsilon)^{2}+z^{2}\right]^{2}}, \quad f_{2}=\frac{z^{3}}{\left[(x-\varepsilon)^{2}+z^{2}\right]^{2}}$ and

$$
f_{3}=\frac{(x-\varepsilon) z^{2}}{\left[(x-\varepsilon)^{2}+z^{2}\right]^{2}} \text {. }
$$

According to Equation (4), the stress $\left(\sigma_{x}, \sigma_{z}, \tau_{x z}\right)$ contour can be represented with the application of the software Maple, after examining stress distribution of mining floor during the first weighting of main roof.

\section{MINING FLOOR ROCK FAILURE CRITERION}

Many scholars have deeply studied the strength theory of rock, and have put forward some rock failure criterion, such as the Mohr-Coulomb criterion, the Griffith strength theory, the Drucker-Prager criterion, the twin shear unified strength theory, the Tresca's yield criterion and the Miese's yield criterion. Among them, the Mohr-Coulomb criterion is the most concise and most widely used $[14,15]$. For ease and practicality, this paper adopts the Mohr-Coulomb criterion.

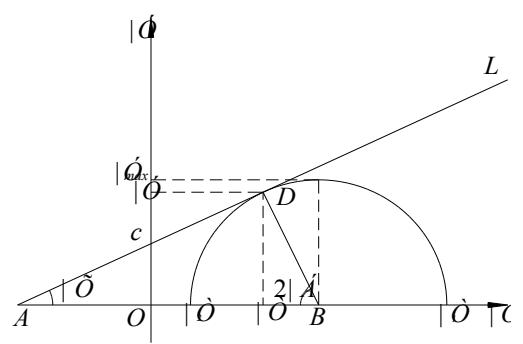

Fig. (3). The Mohr-Coulomb criterion in coordinates $\sigma-\tau$.

As shown in Fig. (3), in the light of the Mohr-Coulomb criterion, if intensity curve AL intersects or touches the stress circle, i.e. point $\mathrm{B}\left(\frac{\sigma_{1}+\sigma_{2}}{2}, 0\right)$, which is less than or equal to $\frac{\sigma_{1}-\sigma_{2}}{2}$ away from line $\mathrm{AL}$, then the rock failure is observed. This relationship can be represented by the following inequality

$$
\left(\frac{\frac{\sigma_{1}+\sigma_{2}}{2} \tan \varphi+c}{\sqrt{\tan ^{2} \varphi+1}}\right) \leq \frac{\sigma_{1}-\sigma_{2}}{2}
$$

Equation (5) can be further written as

$$
\left\{\begin{array}{l}
\tau_{\max }=\frac{\sigma_{1}-\sigma_{2}}{2}=\sqrt{\frac{\left(\sigma_{x}-\sigma_{z}\right)^{2}}{2}+\tau_{x z}^{2}} \\
\sigma_{1}+\sigma_{2}=\sigma_{x}+\sigma_{z}
\end{array}\right.
$$

Where,

$$
\begin{aligned}
& \sigma_{x} \text {--- the horizontal stress of point } \mathrm{M}(\mathrm{x}, \mathrm{z}), \mathrm{Mpa} \\
& \sigma_{z} \text {---the vertical stress of point } \mathrm{M}(\mathrm{x}, \mathrm{z}), \mathrm{Mpa} ; \\
& \sigma_{1} \text {---the maximum principal stress, } \mathrm{Mpa} ; \\
& \sigma_{2} \text {---the minimum principal stress, } \mathrm{Mpa} ; \\
& \varphi \text {---the internal friction angle of floor rock, } \\
& \text { c--- the cohesion of floor rock, Mpa. }
\end{aligned}
$$

Considering equation (6) into equation (5), the failure criterion at any point $(\mathrm{x}, \mathrm{z})$ of floor strata is derived as

$$
\left(\frac{\sigma_{x}+\sigma_{z}}{2} \tan \varphi+c\right) \cos \varphi \leq \sqrt{\frac{\left(\sigma_{x}-\sigma_{z}\right)^{2}}{2}+\tau_{x z}^{2}}
$$

According to Equation (4) and Equation (7), the stress contour and mining damage area of floor strata can be drawn with the application of the software Maple, followed by determining the failure depth of floor rock.

\section{CASE STUDY}

The study was conducted on $180 \mathrm{~m}$ wide face 3612 of a coal mine extract with flat seam, with $610 \mathrm{~m}$ underground depth and $2.61 \mathrm{~m}$ thickness. As the face advances $62 \mathrm{~m}$ from the open - off cut, (AUTHOR: Please review the highlighted and re-phrase for clarity) the first weighting of main roof appears to be accompanied by floor heave under the action of abutment pressure, leading to water invasion. The field measured parameters of the face are: $K_{1}=3, K_{2}=2.5, \gamma$ $=0.025 \mathrm{MN} / \mathrm{m}^{3}, H=610 \mathrm{~m}, a=e=5 \mathrm{~m}, b=d=50 \mathrm{~m}, L=62 \mathrm{~m}$, $\varphi=33^{\circ}, c=1 \mathrm{Mpa}$. According to Equation (4) and Equation (7), the stress contour and mining damaged area of floor strata during the first weighting of main roof were analyzed with the application of the software Maple, as shown in Fig. (4).

As can be seen from Fig. (4), the stress distribution of floor strata during the first weighting of main roof has the following marked characteristics and rules:

(1) Within the scope of abutment pressure, the horizontal stress, vertical stress and shear stress of floor strata concentrate in different degree. The more close the value of abutment pressure to the peal value, the stress concentration is more obvious. While floor strata certainly deep below the gob exhibits stress relief phenomenon, as shown in Figs. (4ac).

(2) Both the horizontal stress and vertical stress contour have the U shape, while shear stress contour has an M shape. That is to say, the floor strata that is certainly deep below the abutment pressure is the stress - concentrated area, while the floor strata that is certainly deep below the gob is stress - 


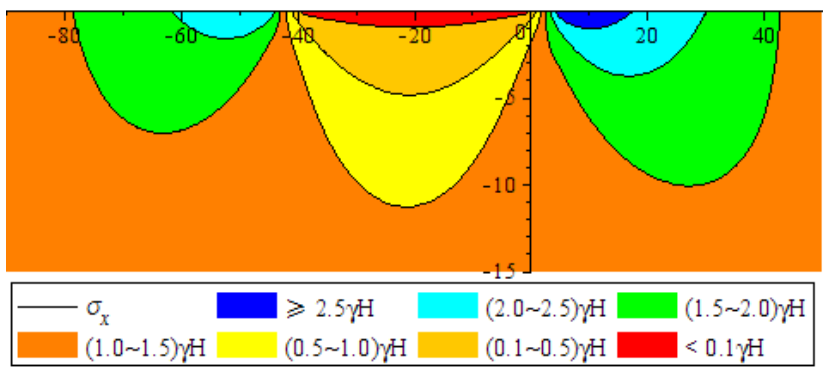

(a)

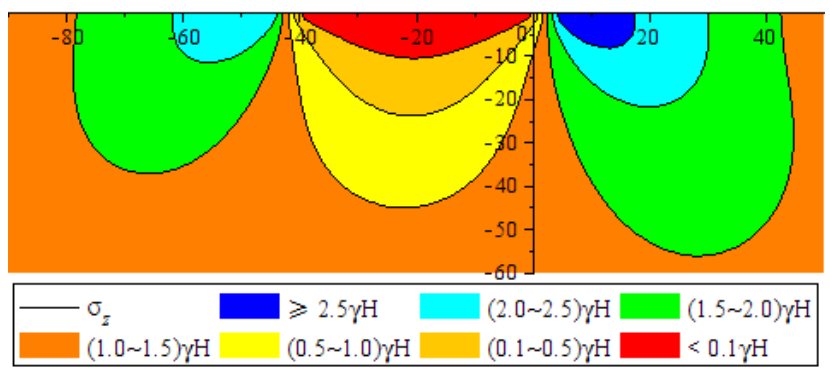

(b)

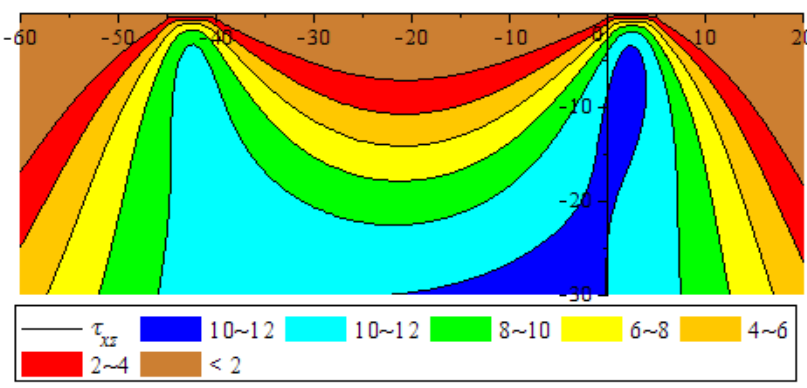

(c)

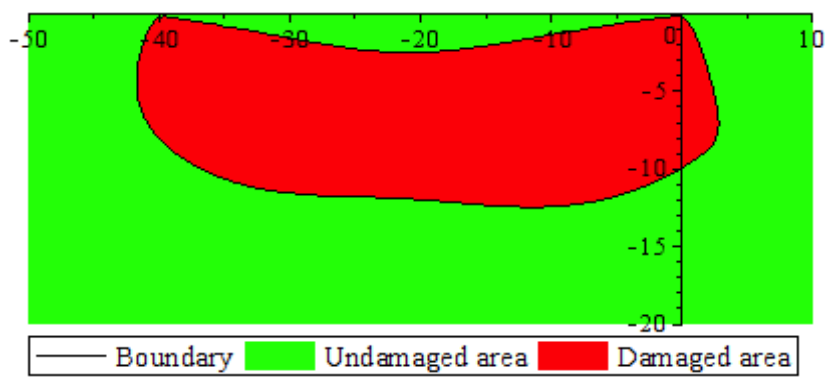

(d)

Fig. (4). The stress contour and mining damage area of floor strata.

relaxed area, and independent stress - concentrated area is the original stress area. (AUTHOR: Please assess if the sentence has been The more close the value of abutment pressure to the peak value, the denser the contour.

(3) The distribution of horizontal stress contour is similar to that of vertical stress contours, but vertical stress is much larger than the horizontal stress at a same depth in the floor. This phenomenon indicates that the scope of vertical stress redistribution caused by abutment pressure is much larger than that of horizontal stress redistribution.

As shown in Fig. (4d), the damaged area of floor strata during the first weighting of main roof seems just like a peasecod. By means of coordinate system, the maximum failure depth of floor is determined to be $12.4 \mathrm{~m}$, which is much close to the measured value $13 \mathrm{~m}$. This damaged area can provide a theory of floor grouting reinforcementbefore the first weighting of main roof.

\section{CONCLUSION}

(1) During the first weighting of main roof, there are both stress concentration and stress relief in the gob floor under the action of abutment pressure, and the influence scope of abutment pressure transmission in floor is limited, while the scope of vertical stress redistribution is much larger than that of horizontal stress redistribution.

(2) With the application of the theory in this paper, the maximum floor failure depth during the first weighting of main roof of face 3612 of a coal mine has been determined to be $12.4 \mathrm{~m}$, which is much close to the measured value $13 \mathrm{~m}$. The caculated damaged area can provide a theory of floor grouting reinforcement before the first weighting of main roof.

\section{CONFLICT OF INTEREST}

The authors confirm that this article content has no conflict of interest.

\section{ACKNOWLEDGEMENTS}

This work was financially supported by the National Natural Science Foundation of China (51304156).

\section{REFERENCES}

[1] W. Hu, and S. Yin, "Dynamic mechanism of water inrush from floor of mining face", Chinese Journal of Rock Mechanics and Engineering, vol. 29, pp. 3344-3349, 2010.

[2] Z. Xu, Y. Sun, S. Gong, and Z. Zhu, "Monitoring and numerical simulation of formation of water inrush pathway caused by coal mining above confined water with high pressure", Chinese Journal of Rock Mechanics and Engineering, vol. 31, no. 8, pp. 1698-1704, 2012.

[3] S. Zhu, Z. Jiang, P. Yao, and W. Xiao, "Application of analytic method in calculating floor stress", Journal of Mining \& Safety Engineering, vol. 24, no. 2, pp. 191-194, 2007.

[4] Z. Gao, and X. Meng, "Study on deformation and fracturing characteristics of seam floor under mining influence", Mining Safety \& Environmental Protection, vol. 37, no. 3, pp. 17-24, 2010.

[5] C. Dai, "Study on the floor water invasion regularity mining on the top of water-perssuerd", M.S. thesis, Anhui University of Science \& Technology, Huainan, ON, China, 2005.

[6] W. Lei, G. Wang, and X. Xue, "Application of finite element strength reduction method to destruction in coal seam floor", Rock and Soil Mechanics, vol. 32, no. 1, pp. 299-303, 2011.

[7] J. Wu, C. Fan, and X. Liu, "Research on mining effect of the No. 6 coal seam Floor in Yangzhuang Coal Mine", Rock and Soil Mechanics, vol. 24, no. 4, pp. 549-552, 2003.

[8] C. Lu, Z. Wang, and Y. Li, "Numerical simulation of water inrush law in coal seam floor with cracks", Rock and Soil Mechanics, vol. 24, pp. 112-116, 2003

[9] Y. Liu, "Numerical analysis of breaking depth of coal floor caused by mining pressure", Journal of Xi'an University of Science and Technology, vol. 28, no. 1, pp. 11-14, 60, 2008.

[10] Y. Jiang, Y. Lu, Y. Zhao, and D. Zhang, "Similar simulation test for breakage law of working face floor in coal mining above aquifer", Chinese Journal of Rock Mechanics and Engineering, vol. 30, no. 8, pp. 1571-1578, 2011. 
[11] J. Wang, Y. Guan, S. Bao, X. Ding, and H. He, "Application of similar material simulation in research of coal seam floor failure regularity", Global Geology, vol. 25, no. 1, pp. 86-90, 2006.

[12] Z. Xu, Elasticity. Beijing, pp. 83-85, 2006.

[13] M. Qiang, P. Shi, and J. Xu, "Mining pressure and strata control", Xuzhou, pp. 121-124, 2010.
[14] M. Cai, "Rock mechanics and Engineering", Beijing, pp. 219-228, 2002.

[15] J. Lv, Y. Cui, J. Liu, and H. Lu, "Analysis of status quo of rock strength theories", Journal of North China University of Technology, vol. 22, no. 1, pp. 73-78, 2010.

Received: June 10, 2015

Revised: July 29, 2015

Accepted: August 15,2015

(C) Zhao et al.; Licensee Bentham Open.

This is an open access article licensed under the terms of the Creative Commons Attribution Non-Commercial License (http://creativecommons.org/licenses/ by-nc/4.0/) which permits unrestricted, non-commercial use, distribution and reproduction in any medium, provided the work is properly cited. 